\title{
Naturally occurring Piper plant amides potential in agricultural and pharmaceutical industries: perspectives of piperine and piperlongumine
}

\author{
Hwang-Ju Jeon, Kyeongnam Kim, Yong-Deuk Kim and Sung-Eun Lee
}

\begin{abstract}
Piperaceae plants consist of about 3600 species, of which about 2000 are Piper plants. Their habitat is distributed across pantropical regions. The representative plant is Piper nigrum, known as black pepper. These plants have been widely used in folk medicine in Korean traditional medicine. This review collected papers identifying and separating the amides obtained from these Piper plants, with a focus on Piper amides potential to control the production and growth of fungal strains that cause plant disease and their insecticidal properties against agricultural pests. Piper amide benefits include antiaflatoxigenic activities, antiparasitic activities, anticancer properties, antiplatelet activities, and anti-inflammatory activities, among other therapeutic properties for the treatment of human diseases. In addition, this review paper provides a total synthesis study on the mass production of Piper amides and their derivatives, with a formulation study for industrial use. This review paper is designed to help inform future studies on Piper amide applications.
\end{abstract}

\section{Introduction}

Piperaceae plants produce natural substances called Piper amides, and extracts of these plants have long been used to treat human diseases in traditional medicine fields in India, China, and Korea. Current research is focused on finding the active ingredients in these extracts. These extracts are also used as insecticides or fungicides in agricultural fields to secure human food productivity. In addition, black pepper is a common table spice and is closely associated with human activity across cultures and regions.

In this review paper, the characteristic amides of each Piper plant were classified based on research papers detailing the separation and purification of these compounds. The biological activities of these amides are briefly introduced, and their inhibitory action and related enzymatic activity are also discussed. These biological

*Correspondence: selpest@knu.ac.kr

School of Applied Biosciences, Kyungpook National University, Daegu 41566, Republic of Korea activities were then divided into agricultural and human disease treatment areas. This review focuses on insecticidal effects, fungicidal effects, effects on diseases mediated by insects such as mosquitoes and flies, anticancer effects in human disease treatment, and anti-inflammatory and anti-thrombotic properties of Piper amides. Among them, piperlongumine was selected to describe in more detail because of its potent biological activity compared to other amides.

\section{Isolation and identification of amides from Piper plants using HPLC}

Qualitative and quantitative analyses of Piper amides are mainly confirmed using the high-performance liquid chromatography (HPLC) method. The active ingredients and plant extracts that have effects as $\mathrm{GABA}_{\mathrm{A}}$ receptor modulators were verified with a fluorometric imaging plate reader (FLIPR) assay using Chinese hamster ovary cells transfected with the $\alpha_{1} \beta_{2} \rho_{2}$ subunit of $\mathrm{GABA}_{\mathrm{A}}$ receptor, designed to test multiple plant extracts and active compounds [1] (Fig. 1). Piperine 
(1) was separated by HPLC from the $0.4-1.2 \mathrm{mg}$ of Piper nigrum extract and showed an $\mathrm{EC}_{50}$ value of $5.76 \pm 0.7 \mu \mathrm{M}$ as $\mathrm{GABA}_{\mathrm{A}}$ receptor modulator.

Recently, a study on the metabolic processes of piperine, piperlongumine (2), and pellitorine (3), the major pharmaceutical ingredients of Piper longum, was conducted using HPLC-LTQ-Orbitrap MS [2]. Authors compared and confirmed metabolites of the three natural Piper amides using liver microsomes of humans, rhesus monkeys, beagles, rats, and mice. Piperine was degraded, and three metabolites were identified, two types of piperlongumine, and one type of pellitorine. Major metabolites were derived through demethylation and oxidation reactions on the methylenedioxy group in the amide molecular structures, and differences among species were revealed therein.

The permeability of $\mathrm{GABA}_{\mathrm{A}}$ modulators in naturally occurring compounds enabling passage through the blood-brain barrier (BBB) was evaluated using three different types of experimental BBB models, immortalized hBMEC cells, an endothelial cell model similar to a human brain, and primary cell models with co-cultures of bovine endothelial cells and rat astrocytes [3]. Evidence suggested that piperine could enter the brain through the BBB, as determined by UHPLC-MS/MS, in the range of 5 to $500 \mathrm{ng} / \mathrm{mL}$ levels in the matrix.

Another study reported on qualitative and quantitative analyses of 18 major alkaloids found in Piper longum using UHPLC-DAD-MS [4]. In this study, 25 amide alkaloids were analyzed, and researchers confirmed that piperine, pipernonaline (4), guineensine (5), and $N$-isobutyl-2-E,4E-octadecadienamide (6) could be used as representative markers of $P$. longum amides. These four amide alkaloids were assessed and quantified as $57.7 \mathrm{mg} / \mathrm{g}$ for piperine, $65.6 \mathrm{mg} / \mathrm{g}$ for pipernonaline, $17.7 \mathrm{mg} / \mathrm{g}$ for guineensine, and $23.9 \mathrm{mg} / \mathrm{g}$ for $N$-isobutyl-2-E,4E-octadecadienamide in the alkaloid fraction of $P$. longum. Their results also indicated that HPLC could accurately quantify amides contained in the solvent fraction of the Piper plant and could be used to promote standardization in herbal medicine.

A study was also conducted on Thai traditional medicines referred to as Benjakul, which include five plant extracts: . chaba, $P$. sarmentosum, $P$. interruptum, Plumbago indica, and Zingiber officinale [5]. Among them, naturally occurring substances with high cytotoxicity against the human small lung cancer cell line NCI-HI 688 were isolated by HPLC from the hexane solvent fraction of Benjakul ethanol extract. The compound with the highest content was piperine, and that with the highest cytotoxicity was plumbagin, with an $\mathrm{IC}_{50}$ value of $1.41 \pm 0.01 \mu \mathrm{g} / \mathrm{mL}$.

As described above, qualitative and quantitative analyses of Piper amide frequently employ HPLC for a range of purposes, predominantly to identify the types of amide in each plant and define their chemical fingerprints. This includes a study that analyzed the amides produced by different components of the $P$. ovatum plant

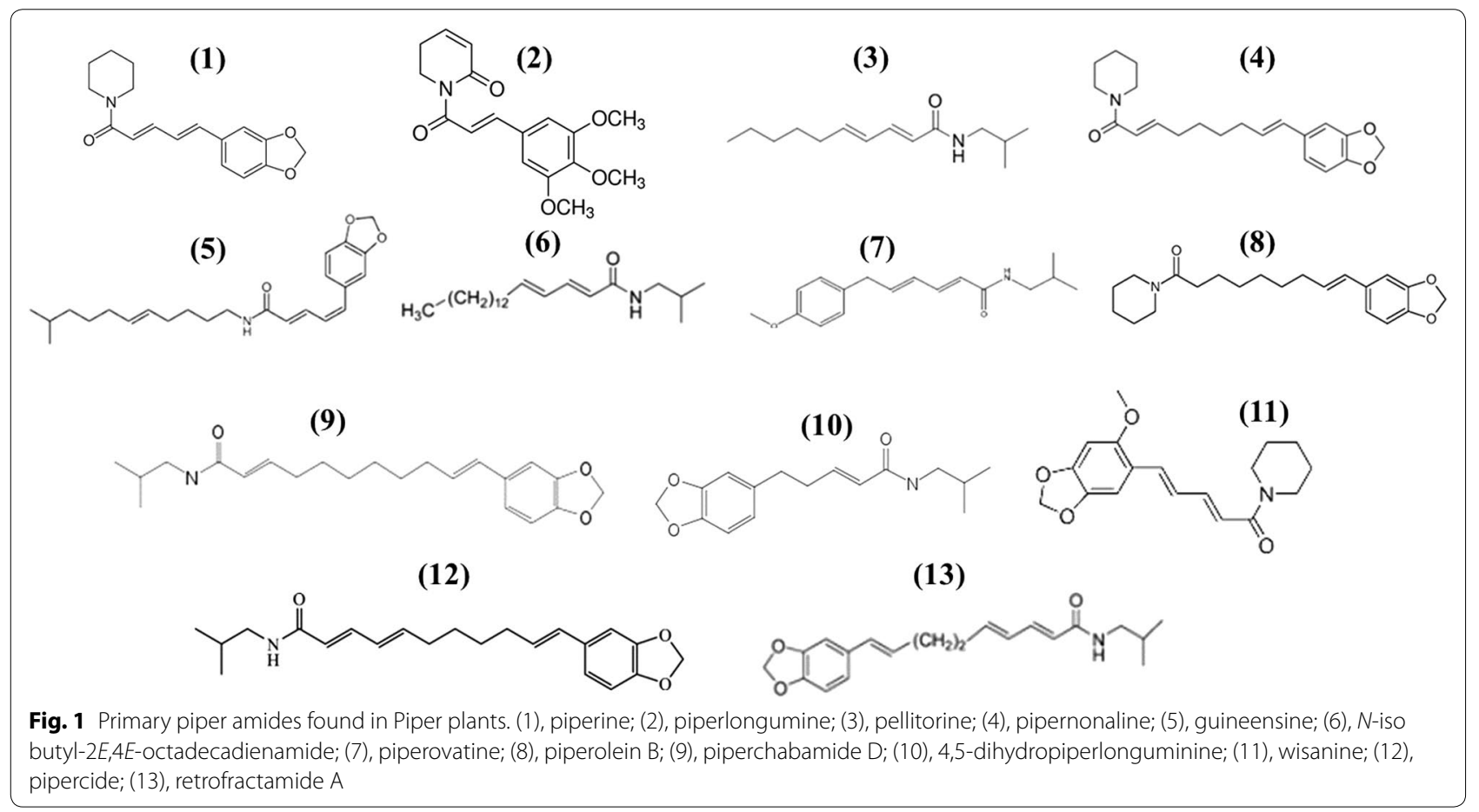


[6]. P. ovatum has been used in traditional medicine to relieve inflammation and provide analgesia, and the study reported how much of the amide compounds were distributed among hydroethanolic fractions of the leaves, stems, and roots of the plant. Piperlongumine was used as a standard material, and method validation was conducted to establish optimal experimental conditions. Under these analytical conditions, piperlongumine and piperovatine (7) were each identified in all of the components of $P$. ovatum using HPLC, indicating it is suitable for routine quantitative analysis of amides in plant extracts.

\section{Insecticidal amides from Piper plants}

The amides derived from Piper plants have been reported to have many insecticidal properties that could be applied to control insect pests on agricultural fields. This section introduces certain amides possessing insecticidal capacity and the Piper plants in which they are found.

Recently, larvae from the diamondback moth (Plutella xylostella) were exposed to two newly isolated amide compounds from P. nigrum, piperolein B (8) and piperchabamide D (9); these compounds demonstrated $96.7 \%$ and $79.2 \%$ mortality, respectively, at a concentration of $0.1 \mathrm{mg} / \mathrm{mL}$ [7]. The duration of exposure to the material under these experimental conditions was 4 days. On the basis of these results, these compounds were suggested as potential alternatives to synthetic pesticides currently in use.

In another study, pellitorine and 4,5-dihydropiperlonguminine (10) were isolated from $P$. tuberculatum to assess their control of the velvetbean caterpillar (Anticarsia gemmatalis). These compounds were potent at 200 and $700 \mu \mathrm{g} /$ insect for pellitorine and 4,5-dihydropiperlonguminine, respectively [8]. $\mathrm{LD}_{50}$ values were then obtained for the two amides and found to be 31.3 and $122.3 \mu \mathrm{g} /$ insect for pellitorine and 4,5-dihydropiperlonguminine, respectively.

Another study exposed Musca domestica and Drosophila melanogaster to the ethyl acetate fraction of $P$. nigrum containing insecticidal amides and assessed differential gene expression in D. melanogaster after the treatment to uncover genes whose expression levels varied by at least a factor of two using cDNA microarray analysis [9]. Among them, cytochrome P450 isozymes, including Cyp 6a8, Cyp 9b2, and Cyp 12d1, were at least two-fold upregulated in the $P$. nigrum-treated groups. Based on these results, cytochrome $\mathrm{P} 450$ was proposed as an enzyme that participated in the decomposition of amides [10].

Similarly, P. nigrum plants have been reported to have many amide-based substances with insecticidal effects, including wisanine (11) and piptigrine, which exhibited pesticidal activity at the $30 \mathrm{ppm}$ and $15 \mathrm{ppm}$ levels, respectively, on the fourth instar of Anopheles aegypti $[11,12]$. As mentioned above, Piper amides have strong insecticidal capacities, which can lead to larvae mortality of mosquitoes, a significant disease vector to humans. Below, we provide a list of studies demonstrating insecticidal effects on mosquito larvae. In recent years, insect pests have developed comprehensive resistance to currently used insecticides, causing breakdowns in insect control. This common phenomenon occurs in mosquitoes and many other insect pests, and the studies detail the results of using natural amides to control mosquitoes possessing resistance to conventional insecticides.

Samuel et al. [13] reported that piperine, a representative amide in $P$. nigrum, had been used to control insecticide-resistant and susceptible strains of Anopheles mosquitoes. Strains of Anopheles spp. were An. arabiensis, An. coluzzii, An. gambiae, An. quadriannulatus, and An. funestus. Anopheles strains resistant and susceptible to insecticides were found to be susceptible to black pepper and piperine, suggesting these compounds could be an alternative to currently used larvicides to control mosquito larvae.

Insecticidal effects on Culex pipiens pallens and Aedes aegypti female adults were examined using piperine and the isobutylamides pellitorin, guineensine, pipercide (12), and retrofractamide A (13) from P. nigrum [13]. Among them, pellitorine was the most toxic compound, at $0.4 \mu \mathrm{g} /$ female $C$. pipiens adult, followed by guineensine, retrofractamide $\mathrm{A}$, and pipercide. The positive insecticide, chlorpyrifos, was potent at $0.03 \mu \mathrm{g} /$ female insect, about 10 times lower than currently used insecticides, suggesting natural amides could be potent insecticides in the field. Another important Piper plant, P. longum, produces pipyahyine, which was isolated and purified as a new mosquito larvicidal amide [14]. Its $\mathrm{LC}_{50}$ and $\mathrm{LC}_{90}$ values were 1.03 and $2.04 \mathrm{ppm}$, respectively, against fourth instar larvae of C. quinquefasciatus.

\section{Antifungal and antiparasitic amides from Piper plants}

Sixteen natural substances have been successfully isolated from the roots of $P$. sarmentosum, of which sarmentamide $\mathrm{A}, \mathrm{B}$, and $\mathrm{C}$ were the first to be reported. Sarmentine and sarmentosine showed strong inhibitory effects against Plasmodium falciparum (K1 type, a multidrug resistant strain) with $\mathrm{EC}_{50}$ values of 4.5 and $3.9 \mu \mathrm{g} / \mathrm{mL}$, respectively [15]. Among them, brachyamide $\mathrm{B}$ and sarmentosine exhibited potent antifungal activities against Candia albicans as evaluated by formazan assay method, with $\mathrm{EC}_{50}$ values of 41.82 and $32.82 \mu \mathrm{g} / \mathrm{mL}$, respectively.

Piper amides have been shown to inhibit the growth of mycotoxin-producing fungi and their production of 
mycotoxins, especially aflatoxin and ochratoxin. Aflatoxin is mainly produced by Aspergillus flavus and $A$. parasiticus, and ochratoxin by Aspergillus ochraceus. The Piper amides that inhibited the growth of A. flavus (WRRC-3-90-42-12) included piperine, piperlongumine, pipernonaline, and piperoctadecalidine [16]. These amides are mainly found in $P$. longum and $P$. nigrum. Piperlongumine demonstrated a potent inhibitory effect on the growth of A. flavus at a concentration of $0.2 \%$, and antiaflatoxigenic activity at a concentration of $0.1 \%$. Similarly, piperine and piperlongumine completely inhibited the production of ochratoxin $\mathrm{A}$, ochratoxin $\mathrm{B}$, and citrinin at a concentration of only $0.001 \%$ in A. auricomus, A. sclerotiorum, and A. alliaceus. When curcumin was used in combination with these compounds, growth of $A$. alliaceus was inhibited by approximately $70 \%$ at a concentration of $0.1 \%$, while the production of ochratoxin A was inhibited at a concentration of $0.01 \%$ [17].

New isobutyl amides were isolated from two other Piper plants, P. scutifolium and P. hoffmanseggianum, identified as scutifoliamide A and scutifoliamide B, respectively. Ten substances isolated from these two plants were assessed for their antifungal activities by thin-layer chromatographic plate method against $\mathrm{Cla}$ dosporium cladosporioides and C. sphaerospermum; among them, isopiperlongumine demonstrated antifungal activity at a concentration of $0.25 \mu \mathrm{g}$ [18]. Antifungal amides were also isolated from the Piper plants Piper flaviflorum and Piper sarmentosum, three of which were new, piperflaviflorine A, piperflaviflorine B, and sarmentamide D. Antifungal activity $\mathrm{IC}_{50}$ values for these substances ranged from 4.7 to $20.0 \mathrm{mg} / \mathrm{mL}$ [19].

Many studies have introduced natural substances from Piper species demonstrating antifungal activities, and among them, piperlongumine has been reviewed for several biological activities, especially as an antifungal [2022]. Papers describe antiparasitic activities, including leishmanicidal, trypanocidal, and schistosomicidal activities, among Piper amides. Of these, Leishmania is a type of parasite in the paraphyletic group that enters the body of human or rodent hosts via sandflies. Infection can lead to the development of the difficult-to-treat leishmaniasis.

Leishmanicidal amides isolated from $P$. longum include piperlongumine, 1-(3,4-methylenedioxyphenyl)- $1 E$ tetradecene, piperlongumine A, $2 E, 4 E-N$-isobutyl-octadecenamide, piperlongumine $\mathrm{B}, 2 E, 4 E-N$-isobutyl-dodecenamide, $2 E, 4 E, 12 E, 13$-(3,4-methylenedioxyphenyl)-tridecatrienoic acid isobutyl amide, and piperine. Among them, piperine has an $\mathrm{IC}_{50}$ value of $3.15 \mu \mathrm{g} / \mathrm{mL}$, showing strong leishmanicidal effect. This effect was stronger than that of miltefosine $\left(\mathrm{IC}_{50}\right.$ value, $\left.8.20 \mu \mathrm{g} / \mathrm{mL}\right)$ used as a positive control [23]. The strong leishmanicidal activity of piperlongumine has been reported in many of the review papers mentioned above [21], and recently, piperlongumine showed $\mathrm{IC}_{50}$ values against promastigote forms of Leishmania infantum and L. amazonensis of 7.9 and $3.3 \mu \mathrm{M}$, respectively. For the amastigote form of $L$. amazonensis, the $\mathrm{IC}_{50}$ value of piperlongumine was $0.4 \mu \mathrm{M}$ [24]. Recently, a study was conducted to measure the synergistic effects of piperine and capsaicin with meglumine antimoniate towards promastigote and amastigote stages of Leishmania infantum [25]. These experiments found even stronger $\mathrm{EC}_{50}$ values $(4.31 \pm 0.44 \mu \mathrm{g} / \mathrm{mL}$ for promastigote form; $7.25 \pm 4.84 \mu \mathrm{g} /$ $\mathrm{mL}$ for amastigote form) and the authors recommended combining them with currently used prescription drugs.

\section{Pharmaceutical activities of amides from Piper plants to treat human diseases \\ Anticancer amides from Piper plants}

Piper amides have demonstrated strong cytotoxic effects on many cancer cells, and may be used as primary substances to treat cancer in the future; these will be discussed in detail in this review. In particular, the effects of piperlongumine are unusual, with anticancer properties at low concentrations. Recently, 32 substances with cytotoxic effects among many natural products from Piper plants have been introduced. Of these, 53\% were amides, with piperlongumine showing the most potent effects [26]. Piperlongumine anticancer activity in prostate cancer cells included the inhibition of NF- $\mathrm{kB}$ activity [27], leading to the reduction of translocation of p50 and p65 subunits into the nucleus. The expression levels of various cytokines were also affected by increased concentrations of piperlongumine.

Piperlongumine is known for its unique mechanism of action, generating reactive oxygen species (ROS) to kill cancer cells. Among newly synthesized derivatives, CG-6 exhibited the strongest cytotoxic effect on human prostate cancer DU-145 cells via inhibition of the phosphorylation of STAT2 and IL-6-induced STAT3 phosphorylation [28]. Similarly, another study also reported that piperlongumine induces the production of ROS, resulting in autophagy of biliary cancer cells. Induction of ROS by piperlongumine purportedly occurs by activation of the Erk signaling pathway, and has been shown to induce cell cycle arrest in cholangiocarcinoma cells (HuCCT-1) and gallbladder cancer cells (OCUG 1). Piperlongumine also caused G2/M cell cycle arrest in HuCCT 1 cells and G0/ G1 cell cycle arrest in OCUG 1 cells [29]. Still another study showed an increase in the sensitivity of colorectal cancer cells in association with changes to ROS homeostasis due to inhibition of glutathione production and thioredoxin function by treatment with piperlongumine [30].

The main anti-cancer Piper amides are present in $P$. nigrum. Pellitorine derived from $P$. nigrum possesses 
potent cytotoxic activities against the HL60 human promyelocytic leukemia cell line, with an $\mathrm{IC}_{50}$ value of $13.0 \mu \mathrm{g} / \mathrm{mL}$ [31]. Alkaloids from P. nigrum increase the effect of paclitaxel on cervical cancer cell lines that were resistant to this drug by alkaloid down-regulation of Mcl-1 [32]. Piperine combined with paclitaxel decreased Mcl-1 expression by about $30 \%$ compared to the control cell lines. The anticancer effect of piperine was further confirmed in a human melanoma cell line, wherein piperine increased the expression of BCL2-associated $\mathrm{X}, \mathrm{BAX}$, cleaved ADP-ribose polymerase, and phosphop38; BCL-2 and ERK1/2 phosphorylation were thereby inhibited [33]. Piperine was found to inhibit human ovarian tumor growth by activating the JNK/p38 MAPKmediated intrinsic apoptotic pathway [34]. These effects resulted in increased release of cytochrome $c$ into the cytosol and activation of caspase-3 and -9, all of which are apoptotic facilitators.

The combination of piperine with capsaicin was also potent against doxorubicin-resistant cancer cell lines [35]. Further study is needed to explore how to combine piperine with other natural materials to treat cancer cells that have developed resistance to conventional anticancer drugs. Interestingly, piperine-free $P$. nigrum extracts were prepared to study their effects on $N$-nitrosomethylurea-induced mammary tumorigenesis in rats [36]. Recently, a review paper was published that collected results from several studies on the anticancer effects of piperine towards cancerous and normal cells [37].

\section{Antiplatelet activities of Piper amides}

Antiplatelet effects by solvent extracts of Piper plants have been suggested, and a study on the antiplatelet mechanisms in these extracts was undertaken to assess their inhibition of prostaglandin and leukotriene biosynthesis via the reduction of 5-lipoxygenase and cyclooxygenase activity [38]. Among them, extracts from Piper boehmeriifolium var. tonkinense possessed the strongest anti-platelet activity; the active compounds in the extracts were identified as pellitorine, piperlongumine, and piperine, among others.

Antiplatelet effects of piperlongumine have been reported by many research groups. Their results indicated that piperlongumine suppressed platelet aggregation in rabbits as a thromboxane A2 receptor antagonist [39]. Another study reported on inhibiting aggregation by treating with piperlongumine after generating platelet aggregation using collagen, arachidonic acid, and platelet-activating factor [40]. The antiplatelet effects of synthesized piperlongumine derivatives were also measured; among these derivatives, 1-(3,5-dimethylpiperidin-1-yl)3-(3,4,5-trimethoxyphenyl) prop-2-en-1-one was identified as the most potent.
A proteomics study was conducted wherein piperlongumine was administered to collagen-treated, aggregated rabbit platelet cells [41]. After piperlongumine treatment of the platelet cells, the levels of 33 proteins in the aggregated cells decreased, and those of 24 proteins increased. Antithrombogenic effects of piperlongumine were measured using mice after intravenous (IV) injection of a combination of collagen and epinephrine, and protection by piperlongumine was evaluated at $47.9 \%, 8.6 \%$ higher than the aspirin used as a positive control.

\section{Other therapeutic activities of Piper amides}

$P$. chaba contains several amide compounds, and of these, four newly isolated amides (piperchabamides A, B, C, and D) were identified. These four amides, along with other previously identified amides, showed therapeutic effects on ethanol-induced gastric lesions [42]. Anti-inflammatory properties of amides derived from $P$. ovatum have been reported in croton oil-induced ear edema in mice, using a combinatorial mixture of piperovatine and piperlongumine at doses of 2.5, 1.25, and $0.625 \mathrm{mg} /$ ear; these treatments dramatically controlled levels of ear edema [43]. Another amide of P. longum, methylpiperate, is a potent inhibitor of monoamine oxidase (MAO). MAO exists in two isozymes, and inhibitors for MAO-A have been used as anti-depressants. MAO-B inhibitors have been used in the treatment of Alzheimer's disease. Methylpiperate exhibited dramatic MAO inhibitory activity, with an $\mathrm{IC}_{50}$ value of $3.6 \mu \mathrm{M}$, and demonstrated competitive inhibition against both MAO-A and MAO-B as assessed with Lineweaver-Burk plots [44]. Two other Piper amides (piperlongumine and retrofractamide $\mathrm{A}$ ) have shown inhibitory effects on histone deacetylase activity, and a hydroxamic acid moiety is needed to show their potent inhibition of HDAC activity [45].

Other biological activities of piperlongumine include the inhibition of atherosclerotic plaque formation and suppression of the proliferation of vascular smooth muscle cells [46]. These effects on atherosclerosis by piperlongumine are related to its ability to inhibit platelet-derived growth factor BB-induced proliferation, conferring down-regulation of downstream signaling molecules. Studies have also shown that piperlongumine postpones the activation of NF-KB. Another important physiological activity of piperlongumine is as an activator for the phosphorylation of AMP-activated protein kinase [47]. After oral administration, piperlongumine markedly enhanced object recognition and building behavior in aged mice, suggesting therapeutic effects on hippocampal function and cognitive decline [48]. Similarly, liposaccharide (LPS)-induced amyloidogenesis is caused by NF-kB 


\section{$(8)$ \\ Piper amides \\ Agricultral view \\ Inseticidal \\ Fungicidal \\ Mosquito larvicidal \\ Anti-bacterial properties

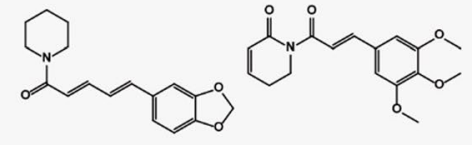 \\ (e.g. Piperine and Piperlongumine)

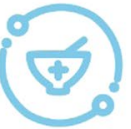 \\ Pharmaceutical view \\ Anti-cancer \\ Anti-platelet \\ Anti-inflammatory \\ Antiparasitic \\ other therapeutic properties}

Fig. 2 Roles of piper amides derived from Piper plants in agricultural and pharmaceutical aspects

activity. Piperlongumine can inhibit amyloidogenesis by inhibiting NF-kB activity. Evidence also suggests that piperlongumine injections inhibited LPS-induced memory [49].

These multiple biological effects led to a study undertaking formulations of piperlongumine to prepare it for use as a medicinal therapeutic [50] (Fig. 2). The solubility of piperlongumine increased 27 -fold when $10 \%$ polysorbate 80 was used as a surfactant. The solution was unstable at pH 7 and above, but favorably stable at pH 4 and below. Another study confirmed that it takes about 17 weeks to decompose about $10 \%$ of the piperlongumine formulation at $\mathrm{pH} 4$ in $25{ }^{\circ} \mathrm{C}$ conditions. Finally, piperlongumine formulated into ROS-sensitive nanofibers was found to suppress the growth of cholangiocarcinoma cells [51].

\section{Acknowledgements}

Not applicable.

\section{Authors' contributions}

$\mathrm{H}-J J, K K$ and S-EL wrote the draft manuscript. $\mathrm{H}-J$ J and KK conducted drawings of Fig. 2. H-JJ, Y-DK and S-EL conducted the correction of draft manuscript. $\mathrm{H}-J \mathrm{~J}, \mathrm{KK}$ and S-EL inspired the overall writings and revised the final manuscript. All authors read and approved the final manuscript.

\section{Funding}

This study was supported by Kyungpook National University Research Fund (2017).

\section{Availability of data and materials}

The datasets used and/or analyzed during the current study are available from the corresponding author on reasonable request.

\section{Competing interests}

The authors declare that they have no competing interests.

Received: 28 September 2019 Accepted: 16 October 2019 Published online: 04 November 2019

\section{References}

1. Faleschini MT, Maier A, Fankhauser S, Thasis K, Hebeisen S, Hamburger M, Butterweck V (2019) A FLIPR assay for discovery of GABAA receptor modulators of natural origin. Plant Med 85:925-933

2. He H, Guo WW, Chen XQ, Zhao HY, Wu X (2019) Comparative metabolism of three amide alkaloids from Piper longum in five different species of liver microsomes. Zhongguo Zhong Yao Za Shi 14:3084-3089
3. Eigenmann DE, Dürig $C$, Jähne EA, Smieško $M$, Culot $M$, Gosselet F, Cecchelli R, Helms HCC, Brodin B, Wimmer L, Mihovilovic MD, Hamburger M, Oufir M (2016) In vitro blood-brain barrier permeability predictions for GABAA receptor modulating piperine analogs. Eur J Pharm Biopharm 103:118-126

4. Li K, Fan Y, Wang H, Fu Q, Jin Y, Liang X (2015) Qualitative and quantitative analysis of an alkaloid fraction from Piper longum $\mathrm{L}$. using ultra-high performance liquid chromatography-diode array detector-electrospray ionization mass spectrometry. J Pharm Biomed Anal 109:28-35

5. Rattarom R, Sakpakdeejaroen I, Hansakul P, Itharat A (2014) Cytotoxic activity against small cell lung cancer cell line and chromatographic fingerprinting of six isolated compounds from the ethanolic extract of Benjakul. J Med Assoc Thai 97(Suppl 8):S70-S75

6. Silva DR, Brenzan MA, Kambara LM, Cortez LE, Cortez DA (2013) Analysis of amide compounds in different parts of Piper ovatum Vahl by highperformance liquid chromatographic. Pharmacogn Res 5(4):254-259

7. Hwang KS, Kim YK, Park KW, Kim YT (2017) Piperolein B and piperchabamide D isolated from black pepper (Piper nigrum L.) as larvicidal compounds against the diamondback moth (Plutella xylostella). Pest Manag Sci 73(8):1564-1567

8. Navickiene HM, Miranda JE, Bortoli SA, Kato MJ, Bolzani VS, Furlan M (2007) Toxicity of extracts and isobutyl amides from Piper tuberculatum: potent compounds with potential for the control of the velvet bean caterpillar, Anticarsia gemmatalis. Pest Manag Sci 63(4):399-403

9. Jensen HR, Scott IM, Sims S, Trudeau VL, Arnason JT (2006) Gene expression profiles of Drosophila melanogaster exposed to an insecticidal extract of Piper nigrum. J Agric Food Chem 54(4):1289-1295

10. Siddiqui BS, Gulzar T, Begum S, Afshan F, Sattar FA (2005) Insecticidal amides from fruits of Piper nigrum Linn. Nat Prod Res 19(2):143-150

11. Siddiqui BS, Gulzar T, Begum S, Afshan F (2004) Piptigrine, a new insecticidal amide from Piper nigrum Linn. Nat Prod Res 18(5):473-477

12. Samuel M, Oliver SV, Coetzee M, Brooke BD (2016) The larvicidal effects of black pepper (Piper nigrum L.) and piperine against insecticide resistant and susceptible strains of Anopheles malaria vector mosquitoes. Parasites Vectors 9:238

13. Park IK (2012) Insecticidal activity of isobutylamides derived from Piper nigrum against adult of two mosquito species, Culex pipiens pallens and Aedes aegypti. Nat Prod Res 26(22):2129-2131

14. Madhu SK, Vijayan VA, Shaukath AK (2011) Bioactivity guided isolation of mosquito larvicide from Piper longum. Asian Pac J Trop Med 4(2):112-116

15. Tuntiwachwuttikul P, Phansa P, Pootaeng-On Y, Taylor WC (2006) Chemical constituents of the roots of Piper sarmentosum. Chem Pharm Bull 54(2):149-151

16. Lee SE, Mahoney NE, Campbell BC (2002) Inhibition of aflatoxin B1 biosynthesis by piperlongumine isolated from Piper longum L. J Microbiol Biotechnol 12(4):679-682

17. Lee SE, Park BS, Bayman P, Baker JL, Choi WS, Campbell BC (2007) Suppression of ochratoxin biosynthesis by naturally occurring alkaloids. Food Addit Contam 24(4):391-397

18. Marques JV, Kitamura RO, Lago JH, Young MC, Guimarães EF, Kato MJ (2007) Antifungal amides from Piper scutifolium and Piper hoffmanseggianum. J Nat Prod 70(12):2036-2039 
19. Shi YN, Liu FF, Jacob MR, Li XC, Zhu HT, Wang D, Cheng RR, Yang CR, Xu M, Zhang YJ (2017) Antifumgal amide alkaloids from the aerial parts of Piper flaviforum and Piper sarmentorum. Planta Med 83(1-2):143-150

20. Xu WH, Li XC (2011) Antifungal compounds from Piper species. Curr Bioact Compd. https://doi.org/10.2174/157340711798375822

21. Bezerra DP, Pessoa C, de Moraes MO, Saker-Neto N, Silveira ER, CostaLotufo LV (2013) Overview of the therapeutic potential of piplartine (piperlongumine). Eur J Pharm Sci 48(3):453-463

22. Durant-Archibold AA, Santana Al, Gupta MP (2018) Ethnomedical uses and pharmacological activities of most prevalent species of genus Piper in Panama: a review. J Ethnopharmacol 217:63-82

23. Sahi S, Tewatia P, Ghosal S (2012) Leishmania donovani pteridine reductase 1: comparative protein modeling and protein-ligand interaction studies of the leishmanicidal constituents isolated from the fruits of Piper longum. J Mol Model 18(12):5065-5073

24. Moreira FL, Riul TB, Moreira ML, Pilon AC, Dias-Baruffi M, Araújo MSS, Lopes NP, de Oliveira ARM (2018) Leishmanicidal effects of piperlongumine (piplartine) and its putative metabolites. Planta Med 84(15):1141-1148

25. Vieira-Araújo FM, Macedo Rondon FC, Pinto Vieira ÍG, Pereira Mendes FN, Carneiro de Freitas JC, Maia de Morais S (2018) Sinergism between alkaloids piperine and capsaicin with meglumine antimoniate against Leishmania infantum. Exp Parasitol 188:79-82

26. Wang YH, Morris-Natschke SL, Yang J, Niu HM, Long CL, Lee KH (2014) Anticancer principles from medicinal Piper (hú jiāo) plants. J Tradit Complement Med 4(1):8-16

27. Ginzburg S, Golovine KV, Makhov PB, Uzzo RG, Kutikov A, Kolenko VM (2014) Piperlongumine inhibits NF-KB activity and attenuates aggressive growth characteristics of prostate cancer cells. Prostate 74(2):177-186

28. Kim YH, Yoon YJ, Lee YJ, Kim CH, Lee S, Choung DH, Han DC, Kwon BM (2018) Piperlongumine derivative, CG-06, inhibits STAT3 activity by direct binding to STAT3 and regulating the reactive oxygen species in DU145 prostate carcinoma cells. Bioorg Med Chem Lett 28(14):2566-2572

29. Chen SY, Huang HY, Lin HP, Fang CY (2019) Piperlongumine induces autophagy in biliary cancer cells via reactive oxygen species-activated Erk signaling pathway. Int J Mol Med. https://doi.org/10.3892/ ijmm.2019.4324

30. Wang H, Jiang H, Corbet C, de Mey S, Law K, Gevaert T, Feron O, De Ridder M (2019) Piperlongumine increases sensitivity of colorectal cancer cells to radiation: involvement of ROS production via dual inhibition of glutathione and thioredoxin systems. Cancer Lett 450:42-52

31. Ee GC, Lim CM, Rahmani M, Shaari K, Bong CF (2010) Pellitorine, a potential anti-cancer lead compound against HL6 and MCT-7 cell lines and microbial transformation of piperine from Piper nigrum. Molecules 15(4):2398-2404

32. Xie Z, Wei Y, Xu J, Lei J, Yu J (2019) Alkaloids from Piper nigrum synergistically enhanced the effect of paclitaxel against paclitaxel-resistant cervical cancer cells through the downregulation of Mcl-1. J Agric Food Chem 67(18):5159-5168

33. Yoo ES, Choo GS, Kim SH, Woo JS, Kim HJ, Park YS, Kim BS, Kim SK, Park BK, Cho SD, Nam JS, Choi CS, Che JH, Jung JY (2019) Antitumor and apoptosis-inducing effects of piperine on human melanoma cells. Anticancer Res 39(4):1883-1892

34. Si L, Yang R, Lin R, Yang S (2018) Piperine functions as a tumor suppressor for human ovarian tumor growth via activation of JNK/p38 MAPK-mediated intrinsic apoptotic pathway. Biosci Rep 38(3):BSR20180503

35. Li H, Krstin S, Wang S, Wink M (2018) Capsaicin and piperine can overcome multidrug resistance in cancer cells to doxorubicin. Molecules 23(3):E557
36. Sriwiriyajan S, Tedasen A, Lailerd N, Boonyaphiphat P, Nitiruangjarat A, Deng Y, Graidist P (2016) Anticancer and cancer prevention effects of piperine-free Piper nigrum extract on N-nitrosomethylurea-induced mammary tumorigenesis in rats. Cancer Prev Res 9(1):74-82

37. Manayi A, Nabavi SM, Setzer WN, Jafari S (2018) Piperine as a potential anti-cancer agent: a review on preclinical studies. Curr Med Chem 25(37):4918-4928

38. Stöhr JR, Xiao PG, Bauer R (2001) Constituents of Chinese Piper species and their inhibitory activity on prostaglandin and leukotriene biosynthesis in vitro. J Ethnopharmacol 75(2-3):133-139

39. Iwashita M, Oka N, Ohkubo S, Saito M, Nakahata N (2007) Piperlongumine, a constituent of Piper longum L., inhibits rabbit platelet aggregation as a thromboxane $\mathrm{A}(2)$ receptor antagonist. Eur J Pharmacol 570(1-3):38-42

40. Park BS, Son DJ, Choi WS, Takeoka GR, Han SO, Kim TW, Lee SE (2008) Antiplatelet activities of newly synthesized derivatives of piperlongumine. Phytother Res 22(9):1195-1199

41. Lee SE, Park BS, Huh TL, Lee EW, Yum JH (2010) Proteomic evaluation on antiplatelet activity of piperlongumine derived from Piper longum. Mol Cell Toxicol 6:295-303

42. Morikawa T, Matsuda H, Yamaguchi I, Pongpiriyadacha Y, Yoshikawa M (2004) New amides and gastroprotective constituents from the fruit of Piper chaba. Planta Med 70(2):152-159

43. Rodrigues Silva D, Baroni S, Svidzinski AE, Bersani-Amado CA, Cortez DA (2008) Anti-inflammatory activity of the extract, fractions and amides from the leaves of Piper ovatum Vahl (Piperaceae). J Ethnopharmacol 116(3):569-573

44. Lee SA, Hwang JS, Han XH, Lee C, Lee MH, Choe SG, Hong SS, Lee D, Lee MK, Hwang BY (2008) Methylpiperate derivatives from Piper longum and their inhibition of monoamine oxidase. Arch Pharm Res 31 (6):679-683

45. Luo Y, Liu HM, Su MB, Sheng L, Zhou YB, Li J, Lu W (2011) Synthesis and biological evaluation of piperamide analogues as HDAC inhibitors. Bioorg Med Chem Lett 21(16):4844-4846

46. Son DJ, Kim SY, Han SS, Kim CW, Kumar S, Park BS, Lee SE, Yun YP, Jo H, Park YH (2012) Piperlongumine inhibits atherosclerotic plaque formation and vascular smooth muscle cell proliferation by suppressing PDGF receptor signaling. Biochem Biophys Res Commun 427(2):349-354

47. Ryu J, Kim MJ, Kim TO, Huh TL, Lee SE (2012) Piperlongumine as a potential activator of AMP-activated protein kinase in HepG2 cells. Nat Prod Res 28(22):2040-2043

48. Go J, Park TS, Han GS, Park HY, Ryu YK, Kim YH, Hwang JH, Choi GH, Noh JR, Hwang DY, Kim S, Oh WK, Lee CH, Kim KS (2018) Piperlongumine decreases cognitive impairment and improves hippocampal function in aged mice. Int J Mol Med 42(4):1875-1884

49. Gu SM, Lee HP, Ham YW, Son DJ, Kim HY, Oh KW, Han SB, Yun J (2018) Piperlongumine improves lipopolysaccharide-induced amyloidogenesis by suppressing NF-kappaB pathway. Neuromol Med 20:312-327

50. Aodah A, Pavlik A, Karlage K, Myrdal PB (2016) Preformulation studies on piperlongumine. PLoS ONE 11(3):e0151707

51. Jang HH, Park SB, Hong JS, Lee HL, Song YH, Kim J, Jung YH, Kim C, Kim DM, Lee SE, Jeong YI, Kang DH (2019) Piperlongumine-eluting gastrointestinal stent using reactive oxygen species-sensitive nanofiber mats for inhibition of cholangiocarcinoma cells. Nanoscale Res Lett 14(1):58

\section{Publisher's Note}

Springer Nature remains neutral with regard to jurisdictional claims in published maps and institutional affiliations. 